\title{
Phaeochromocytoma and co-existing Cushing's Disease
}

\author{
Philip C Johnston ${ }^{1}$, Laurence Kennedy ${ }^{1}$, Amir H Hamrahian ${ }^{1}$ Pablo Recinos ${ }^{2}$
}

Department of Endocrinology and Diabetes ${ }^{1}$, Department of Neurosurgery ${ }^{2}$,Cleveland Clinic, Ohio, USA

\section{BACKGROUND}

-Pituitary adenomas (mostly non-functioning or growth hormone secreting) and co-existing phaeochromocytoma have been reported in around 30 cases to date.

-This is the first reported case of co-existing cushing's disease (CD) and pheochromocytoma simultaneously diagnosed.

\section{CASE}

- A 46-year old woman presented with a one year history of bruising, thin skin and weight gain ( $30 \mathrm{lbs})$.

- In addition she reported flushing of her chest, palpitations, heat intolerance and abdominal pain.

- She appeared cushingoid; blood pressure was elevated at $160 / 98 \mathrm{mmHg}$.

- 24 hr UFC $300 \mu \mathrm{g}$ (0-50), ACTH $119 \mathrm{pg} / \mathrm{mL}$ (6-48), midnight salivary cortisol $950 \mathrm{ng} / \mathrm{dL}$ (<100).MRI pituitary:14 x 9mm sellar lesion (Fig.1, arrow).

- Unable to tolerate a CRH test due to a hypertensive episode during the test: high-dose dexamethasone suppression test was not considered necessary.

- Plasma fractionated catecholamines and metanephrines were elevated; norepinephrine 822 $\mathrm{pg} / \mathrm{mL}$ (80-520), epinephrine < $10 \mathrm{pg} / \mathrm{ml}$ (10-200), normetanephrine $1250 \mathrm{pg} / \mathrm{ml} \quad$ (18-101), metanephrine $34 \mathrm{pg} / \mathrm{ml}$ (12-67).

- CT abdomen (Fig 2,arrow) revealed a lipid poor right adrenal mass measuring $36 \times 17 \mathrm{~mm}$ with corresponding Hounsfield units of 47, this was consistent with a phaeochromocytoma, given the elevated metanephrines.

- Treated with phenoxybenzamine prior to elective robotic adrenalectomy, histology confirmed a phaeochromocytoma .

\section{CASE}

- One month post-adrenalectomy plasma fractionated catecholamines and metanephrines were normal. The patient continued to be hypercortisolemic postop.

- Six weeks after adrenal surgery endoscopic transsphenoidal resection of the pituitary mass was performed. The histology revealed an adenoma which was diffusely positive for ACTH, it did not stain with any other anterior pituitary hormones. One day post-op serum cortisol was $1.4 \mathrm{mcg} / \mathrm{dL}$, but ACTH was elevated, $100 \mathrm{pg} / \mathrm{Ml}$.

- 3 months post-pituitary surgery, she had normal plasma metanephrines and 24 hr UFC levels with no visible residual disease on pituitary MRI. However, ACTH remained elevated at $149 \mathrm{pg} / \mathrm{ml}$ (8-42). She is awaiting results of genetic testing.

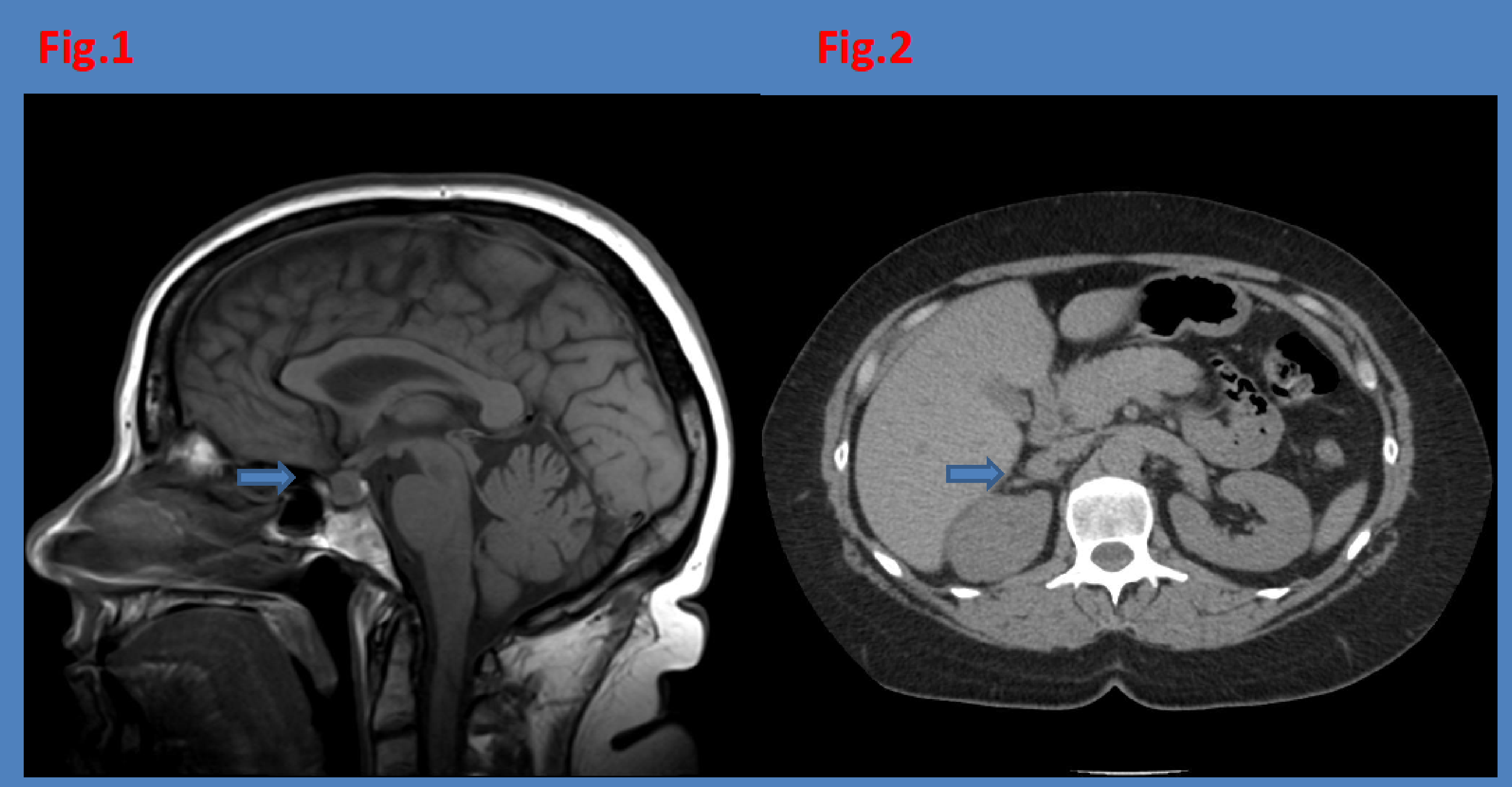

\section{DISCUSSION}

- In this case our first priority was surgical removal of the phaeochromocytoma after adequate alpha blockade because of the risk of a hypertensive crisis if pituitary surgery had been performed first.

-While the presence of pituitary adenoma and phaeochromocytoma can be a coincidental finding, other scenarios such as an 'overlap' or 'variant' of multiple endocrine neoplasia syndrome or a common germline succinate dehydrogenase mutations have been suggested.

\section{CONCLUSION}

Phaeochromocytoma is associated with excess morbidity and mortality if undiagnosed, it was therefore vital that this diagnosis was made prior to pituitary surgery. Clinicians should be alert to the rare association of phaeochromocytoma in patients with clinically significant pituitary adenomas . 